\title{
A New Look and Feel for Chromatographia
}

\author{
Steffen Pauly
}

Published online: 8 January 2011

(C) Springer-Verlag 2011

Regardless of whether readers are holding a printed copy in their hands, or whether they are using the journal online, they will immediately have noticed the changed layout. I hope that readers will appreciate a more colorful appearance. This does not just refer to the use of decorative colors on the cover. Authors will be pleased to learn that their color figures will now appear in the printed issues free of charge. For every article, authors will receive a complimentary e-offprint, that is a PDF of their article with a cover sheet that features the journal cover, the title of the contribution, the author names and full citation details.

These are some of the most obvious and immediate changes connected to the full integration of Chromatographia into Springer's growing portfolio of scientific, technical, and medical (STM) journals alongside such wellreputed publications as "Analytical and Bioanalytical Chemistry" or the "Journal of the American Society for Mass Spectrometry". Until December 2010, Chromatographia was still owned by Springer Fachmedien Wiesbaden $\mathrm{GmbH}$ (formerly Vieweg/Vieweg+Teubner). Legally, the journal now belongs to Springer-Verlag GmbH, Heidelberg, but more importantly it is now a full part of Springer's global publishing activities in science, technology and medicine.

The new look and feel of Chromatographia should provide an attractive stage for the high-quality articles that are published in the journal, selected in the peer review supervised by the Scientific Editors. Their criteria for selecting articles have been clearly described in recent Editorials by Lingeman [1], Smith [2] and Scriba [3]. I fully support the Scientific Editors in maintaining high standards for publication, because only in this way Chromatographia will fulfill its purpose of advancing the readers' knowledge in separation sciences.

As Senior Editor Chemistry, I am developing Springer's programme of books and journals particularly in the analytical sciences. Having been active in analytical science publishing for almost 20 years and collaborating with many members of the Editorial Board on other projects, I look forward to cooperating with the Scientific Editors, The Editorial Advisory Board as well as with the Editorial Office in Wiesbaden, Petra Russkamp and Birgit Borstelmann, on further developing this prestigious journal.

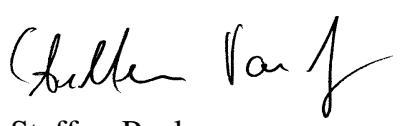

Steffen Pauly

\section{References}

1. Lingeman $H$ (2008) Chromatographia 67:671-672

2. Smith RM (2009) Chromatographia 69:1147-1148

3. Scriba G (2010) Chromatographia 72:595-596 